\title{
HUBUNGAN PEMBERIAN KONSELING KB DENGAN PEMILIHAN ALAT KONTRASEPSI IUD
}

\author{
Herliana \\ Akademi Kebidanan Panca Bhakti Bandar Lampung \\ E-mail : herliana75@gmail.com
}

\begin{abstract}
ABSTRAK
Intera uterine device ( IUD ) merupakan metode kontrasepsi yang digunakan dalam jangka waktu lama, sehingga efektif dalam mencegah kehamilan, kenyataan yang terjadi penggunaan metode kontrasepsi IUD cenderung menurun. Tujuan penelitian ini untuk mengetahui hubungan pemberian konseling KB dengan pemilihan alat kontrasepsi IUD. Penelitian ini bersifat analitik menggunakan rancangan case control, terhadap 200 responden yang terbagi menjadi 100 orang kelompok sampel akseptor IUD dan 100 orang kelompok kontrol tidak menggunakan KB IUD dengan menggunakan Probability Statistick Random Sampling. Alat pengumpulan data menggunakan kuisioner, analisis data dengan uji Chi-sqare. Hasil penelitian menyimpulkan lebih dari separuh responden tidak diberikan konseling KB yaitu 51 responden $(51 \%)$ sebagian responden menggunakan IUD yaitu sebanyak 100 responden dan sebagian responden (50\%). Kesimpulan penelitian yaitu ada hubungan antara konseling KB dengan pemilihan alat kontrasepsi IUD pada akseptor KB ( $p$ value = 0,031), OR sebesar 1,9 artinya ada kemungkinan berpeluang 1,9 kali lebih besar untuk memilih alat kontrasepsi IUD bila di berikan konseling. Petugas kesehatan agar terus meningkatkan pelayanan kesehatan, memberikan konseling dalam mementukan penggunaan alat kontrasepsi , memberikan informasi kepada masyarakat mengenai manfaat dan keuntungannya.
\end{abstract}

Kata Kunci : IUD, Konseling KB, Pemilihan alat kontrasepsi,

\begin{abstract}
Intra uterine device (IUD) is a contraceptive method that is used for a long time, so that it is effective in preventing pregnancy, the fact that the use of IUD contraceptive methods tends to decrease. The purpose of this study was to determine the relationship of family planning counseling with the selection of IUD contraception. This research is analytical using a case control design, for 200 respondents divided into 100 IUD acceptor sample groups and 100 control groups who did not use an IUD using Probability Statistick Random Sampling. Tool for collecting data using questionnaires, analyzing data with Chi-sqare tests. The results of the study concluded that more than half of the respondents were not given family planning counseling, namely 51 respondents (51\%), some respondents used an IUD as many as 100 respondents and some respondents (50\%). The conclusion of the study is that there is a relationship between family planning counseling and the selection of IUD contraceptives in family planning acceptors ( $p$ value $=$ 0.031), an OR of 1.9 means that there is a chance 1.9 times greater chance for IUD contraception if counseled. Health workers are expected to continue to improve health services, provide counseling in determining the use of contraceptives, provide information to the public about the benefits and benefits.
\end{abstract}

Keywords : IUD, Family Planning Counseling, Selection of contraception, 


\section{PENDAHULUAN}

Dalam tiga dasawarsa ini angka kelahiran di Indonesia telah mengalami penurunan secara nyata, dimana pada awal tahun 80-an angka fertilitas total berkisar 5,6 per wanita. Saat ini diperkirakan lebih rendah dari 2,6 anak per wanita usia subur. Penurunan fertilitas di Indonesia belum memberikan kondisi ideal untuk mencapai penduduk tumbuh seimbang karena angka kelahiran total (TFR) masih lebih tinggi dari 2,1 persen secara demografis program Keluarga Berencana masih sangat diperlukan untuk mewujudkan penduduk tumbuh seimbang. Walaupun demikian dari pasangan usia subur 69,8 persen ingin ber-KB namun penggunaan kontrasepsi baru mencapai 60,3 persen. Dari jumlah tersebut 56,7 persen menggunakan kontrasepsi modern dan 3,6 persen menggunakan cara tradisional. Sedangkan pada pasangan usia subur yang tidak ingin punya anak atau menunda kehamilannya tetapi tidak menggunakan kontrasepsi sebesar 8,6 persen dan pasangan usia subur yang kehamilan belum dikehendaki sebesar 7,2 persen. Dari kedua variabel tersebut merupakan indikator akses dan kualitas pelayanan KBKR (BKKBN, 2008).

Pembangunan kependudukan dan keluarga kecil berkualitas merupakan langkah penting dalam mencapai pembangunan berkelanjutan. Hal ini diselenggarakan melalui kuantitas penduduk dan peningkatan kualitas insani dan sumber daya manusia karakteristik pembangunan antara lain dilaksanakan melalui pengendalian pertumbuhan penduduk, keluarga berencana, dan dengan cara pengembangan kualitas penduduk, melalui perwujudan keluarga kecil berkualitas (Depkes RI, 2005).

Ada beberapa hal yang dapat mendukung terwujudnya gerakan KB nasional. Pada tahun 2003 adalah bahwa lebih dari 198.012 orang wanita $(67,53 \%)$ berstatus menikah pernah menggunakan salah satu alat kontrasepsi dan sekitar 1.782 .108 orang wanita $(51,66 \%)$ berstatus menikah sedang menjadi peserta KB aktif (Badan Pusat Statistik, 2003). Dalam pelaksanaannya, program $\mathrm{KB}$ nasional digunakan untuk menunda kehamilan, menjarangkan kehamilan dan menghentikan kehamilan atau kesuburan (Hartanto, 2003).

Hingga tahun 2008 jumlah peserta KB aktif sebanyak 1.051 .000 akseptor, cakupan pelayanan KB sebesar $71,89 \%$ dari PUS 1.461.956. Peserta KB baru sebanyak 309.800 peserta. Dengan rincian IUD: 6.650, implant: 20.400 (35,2\%), MOW: 785, Suntik: 148.550, MOP: 380, Pil: 121.250 dan kondom 11.785 (BKKBN, 2009).

Lampung merupakan salah satu Propinsi di Indonesia yang mampu menyumbangkan 
penurunan laju fertilitas secara nasional. Tingkat fertilitas Propinsi Lampung mengalami penurunan pada tahun 1984 sebesar 4,27 dan pada tahun 2000 telah berubah menjadi 1,68 lebih rendah dari angka nasional sebesar 3,52 (BPS, 2003). Kondisi TFR yang lebih rendah dari angka nasional tersebut membuktikan Propinsi Lampung mempunyai andil yang cukup baik dalam menurunkan angka fertilitas secara nasional.

Pada tahun 2005 jumlah peserta KB baru (PB) di Propinsi Lampung sebanyak 961.428 orang dengan rincian peserta $\mathrm{KB}$ secara MKJP adalah AKDR/IUD yaitu berjumlah 125.106 orang $(45,39 \%)$, IUD berjumlah 123.097 orang $(44.66 \%), \quad \mathrm{MOP} / \mathrm{MOW}$ 27.408 orang $(9,94 \%)$ sedangkan peserta KB non MKJP seperti suntik 337.257 orang $(49,18 \%)$ pil sebanyak 345.310 orang (50.35\%). Sementara pada tahun 2006 didapatkan peningkatan jumlah Perkiraan Permintaan Masyarakat (PPM) untuk menjadi akseptor KB sebanyak 232.550 orang dengan peserta pengguna MKJP yaitu sebanyak 26.585 dimana akseptor KB IUD sebanyak 7.500 orang $(28,21 \%)$, IUD 17.535 orang $(65,96 \%)$, MOP 550 orang $(2,07 \%)$ dan MOW berjumlah 1.000 orang $(3,76 \%)$. Sedangkan peserta pengguna non MKJP yaitu sebanyak 205.965 orang, dimana akseptor KB suntik sebanyak 83.910 orang $(40,74 \%)$, pil 115.700 orang $(56,17 \%)$ dan kondom berjumlah 6.355 orang $(3,09 \%)$.
Selain itu pada tahun yang sama jumlah PB dan KBA serta pengguna KB IUD di Lampung Selatan menempati urutan pertama dan tertinggi di Propinsi Lampung dengan masing-masing berjumlah 29.751 PB dan 229.930 peserta KBA (Profil Kesehatan Provinsi Lampung, 2006).

Di Kabupaten Lampung Selatan didapatkan jumlah peserta KB baru pada tahun 2005 sebanyak 29.582 orang $(12,7 \%)$ dari jumlah PUS sebanyak 232.113 orang, jumlah peserta KB aktif sebanyak 165.543 orang (71,3\%). Kemudian pada tahun 2006 jumlah peserta KB baru bertambah menjadi 29.792 orang dari jumlah PUS sebanyak 233.874 (12,74\%), sementara jumlah peserta KB aktif sebanyak 165.938 orang (70,95\%). Pada tahun 2007 jumlah peserta KB baru di Kecamatan Sidomulyo sebanyak 2465 orang $(41,12 \%)$ dari jumlah PUS yang ada sebanyak 5994 orang, sementara jumlah peserta KB aktif sebanyak 4.324 orang $(72,14 \%)$ (Profil Kesehatan Kabupaten Lampung Selatan, 2008).

Intera Uterine Device (IUD) merupakan metode kontrasepsi yang dapat digunakan dalam jangka waktu yang lama, sehingga efektif penggunaannya dalam mencegah kehamilan, kenyataan yang terjadi penggunaan metode kontrasepsi IUD cenderung menurun sekitar enam persen (BKKBN, 2009). Rendahnya pemakaian 
metode kontrasepsi IUD dikarenakan ketidaktahuan akseptor tentang kelebihan metode tersebut. Ketidaktahuan akseptor tentang kelebihan IUD disebabkan informasi yang disampaikan petugas pelayanan KB kurang lengkap (Bessinger \& Bertrand, 2001).

Puskesmas Sidomulyo yang berada di Wilayah Kabupaten Lampung Selatan juga memberikan pelayanan kontrasepsi kepada akseptor KB. Informasi yang pelayanan KIE pada akseptor $\mathrm{KB}$, dimana salah satunya adalah klien kesulitan memperoleh informasi yang benar dari konselor, sehingga memungkinkan untuk terjadinya salah penilaian (persepsi) terhadap pesan yang disampaikan dengan yang diterima.

Hasil pre survey yang peneliti lakukan pada minggu pertama dan kedua bulan Januari 2010 di Puskesmas Sidomulyo didapatkan 11 orang akseptor KB IUD. Dari 11 orang akseptor KB IUD yang peneliti temui 7 orang diantaranya $(63,63 \%)$ mengatakan bahwa belum mengerti dan mengetahui kelebihan serta kekurangan dari metode kontrasepsi yang sedang digunakan karena tidak mendapatkan KIE secara jelas.

Berdasarkan uraian fenomena tersebut di atas, maka penulis tertarik untuk meneliti mengenai "Hubungan Pemberian konseling KB dengan Pemilihan Alat Kontrasepsi IUD.

\section{METODOLOGI}

Jenis penelitian ini merupakan penelitian kuantitatif menggunakan desain case control, dengan pendekatan “retrospektif". Penelitian ini dilakukan di Puskesmas Sidomulyo Kecamatan Sidomulyo Kabupaten Lampung Selatan. Penelitian akan dilaksanakan pada bulan Maret 2010.

Populasi dalam penelitian ini adalah seluruh akseptor KB yang datang berkunjung ke Puskesmas Sidomulyo Kecamatan Sidomulyo Kabupaten Lampung Selatan. Populasi dalam penelitian ini sebanyak 6.854 orang. Sampel dan kontrol di ambil dari data primer dan sekunder dengan Teknik Probability Random Sampling.

Kelompok Kasus dalam penelitian ini adalah akseptor KB IUD yang masih menggunakan KB IUD yang berkunjung ke puskesmas Sidomulyo kecamatam Sidomulyo Kabupaten Lampung Selatan sebanyak 100 responden

Kelompok kontrol atau pembanding dalam penelitian ini di ambil dari populasi yaitu akseptor KB yang di dak menggunakan IUD yang jumlah nya sama dengan akseptor $\mathrm{KB}$ yang menggunakan alkon IUD sebanyak 100 respon.

Alat ukur yang digunakan untuk konseling adalah angket berupa pertanyaan yang berjumlah 20 item soal. Sedangkan alat ukur 
yang digunakan untuk pemilihan alat kontrasepsi IUD adalah angket yang berupa pertanyaan tentang alat kontrasepsi IUD yang berjumlah 5 item soal.

\section{HASIL}

\section{Analisis Univariat}

Prosentase jawaban responden tentang perbedaan hubungan pemberian konseling $\mathrm{KB}$ dengan Pemilihan Alat kontrasepsi IUD di puskesmas Sidomulyo Kecamatan Sidomulyo Kabupaten Lampung Selatan Tahun 2010

\section{Distribusi Frekuensi Pengguna IUD} Berdasarkan Konseling

Tabel 1. Distribusi Frekuensi Responden dengan IUD Berdasarkan Konseling KB

\begin{tabular}{|c|c|c|}
\hline Konseling & Frekuensi & $\begin{array}{c}\text { Presentase } \\
(\%)\end{array}$ \\
\hline Di berikan & 49 & 49 \\
\hline $\begin{array}{ll}\text { Tidak } & \text { di } \\
\text { berikan } & \end{array}$ & 51 & 51 \\
\hline jumlah & 100 & 100 \\
\hline
\end{tabular}

Berdasarkan tabel diatas ,didapatkan bahwa responden yang menggunakan IUD tidak di berikan konseling yaitu sebanyak 51 responden $(51 \%)$.

Tabel 2. Distribusi Frekuensi Responden dengan Non IUD Berdasarkan Konseling KB

\begin{tabular}{lcc}
\hline Konseling & Frekuensi & $\begin{array}{c}\text { Presentase } \\
(\mathbf{\%})\end{array}$ \\
\hline Di berikan & 33 & 33 \\
\hline $\begin{array}{l}\text { Tidak di } \\
\text { berikan }\end{array}$ & 67 & 67 \\
\hline jumlah & $\mathbf{1 0 0}$ & $\mathbf{1 0 0}$ \\
\hline
\end{tabular}

Berdasarkan table di atas ,di dapatkan bahwa responden yang tidak menggunakan IUD dan tidak di berikan konseling yaitu sebanyak 67 responden $(67 \%)$

\section{Analisis Bivariat}

Analisa bivariat di lakukan guna melihat hubungan pemberian konseling $\mathrm{KB}$ dengan pemilihan Alat Kontrasepsi IUD puskesmas Sidomulyo Kecamatan Sidomulyo Kabupaten Lampung Selatan Tahun 2010 yaitu variabel independen (konseling) dengan variabel dependen (pemilihan alat kontrasepsi IUD) adapun hasil analisa Bivariat adalah sebagai berikut

\section{Hubungan Konseling KB dengan \\ Pemilihan Alat Kontrasepsi IUD}

Tabel 3. Hubungan Konseling dengan Pemilihan Alat Kontrasepsi IUD

\begin{tabular}{|c|c|c|c|c|c|c|c|}
\hline \multirow[t]{3}{*}{ Konseling } & \multicolumn{4}{|c|}{ Pemilihan Alkon IUD } & To & \multirow{3}{*}{$\begin{array}{l}P \\
\text { Val } \\
\text { ue }\end{array}$} & \multirow{2}{*}{$\begin{array}{l}\text { OR } \\
95 \\
\% \\
\text { CI } \\
\end{array}$} \\
\hline & \multicolumn{2}{|c|}{$\begin{array}{l}\text { IUD } \\
\text { ( Kasus) }\end{array}$} & \multicolumn{2}{|c|}{$\begin{array}{l}\text { Non IUD } \\
\text { (control) }\end{array}$} & tal & & \\
\hline & n $\%$ & $\mathrm{n}$ & $\%$ & $\mathrm{~N}$ & $\%$ & & \\
\hline Di berikan & $\begin{array}{ll}4 & 59, \\
9 & 8\end{array}$ & 33 & $\begin{array}{l}40, \\
2\end{array}$ & 82 & $\begin{array}{l}10 \\
0\end{array}$ & 0,03 & 1,9 \\
\hline $\begin{array}{l}\text { Tidak di } \\
\text { berikan }\end{array}$ & $\begin{array}{ll}5 & 43, \\
1 & 2\end{array}$ & 67 & $\begin{array}{l}56, \\
8 \\
\end{array}$ & $\begin{array}{l}11 \\
8\end{array}$ & $\begin{array}{l}10 \\
0 \\
\end{array}$ & 1 & 51 \\
\hline Jumlah & $\begin{array}{ll}1 & 50 \\
0 & \\
0 & \\
& \end{array}$ & $\begin{array}{l}10 \\
0\end{array}$ & 50 & $\begin{array}{l}20 \\
0\end{array}$ & $\begin{array}{l}10 \\
0\end{array}$ & & \\
\hline
\end{tabular}

Berdasarkan tabel di atas, di dapat bahwa pada pemilihan IUD (kasus) ,ada sebanyak 49 $(59,8 \%)$ responden yang di berikan konseling sedangkan pada pemilihan alat kontrasepsi bukan IUD kontrol ada sebnyak 33 (40,2 \%) yang di berikan konseling, hasil uji statistik di peroleh nilai $p$ Value $=0,031$ yang berarti $p<$ 
$\alpha=0,05$, maka dapat di simpulkan bahwa secara statistik ada hubungan yang dengan pemilihan alat kontrasepsi IUD pada akseptor KB di Puskesmas Sidomulyo Kecmatan Sdomulyo Kabupatn Lampung selatan .Hasi analisis juga di patakan nilai Odds Ratio (OR) sebesar 1,9 artinya ada kemungkinan responden yang di beri konseling berrpeluang 1,9 kali lebih besar untuk memilih IUD di banding dengan Responden yang tidak mendapat konseling untuk memilih IUD.

\section{PEMBAHASAN}

Setelah di lakukan analisa dan interprestasi data mengenai hubungan pemberian konseling $\mathrm{KB}$ dengan Pemilihan Alat Kontrasepsi IUD di puskesmas Sidomulyo Kabupaten Lampung Selatan Tahun 2010 Maka di ketahui sebagai berikut :

Berdasarkan tabel 1 di gambarkan bahwa lebih dari separuh responden tidak di berikan konseling yaitu sebanyak 51 responden (51 $\%)$ dan sisanya 49 responden (49 \%) di berikan konseling.

Dari hasil yang di peroleh di ketahui bahwa sebagian responden di berikan konseling dan sisanya tidak di berikan, melihat hasil ini peneliti menilai bahwa yang di berikan oleh tenaga kesehatan belum seluruh nya berhasil. Uraian tersebut tidak sejalan dengan temuan Effendi (1999) yang myatakan bahwa tujuan dari konseling adalah membantu klien untuk memecahkan masalahnya sendiri atau mengusahakan terciptanya suasana yang menimbulkan keberanian untuk memecahkan masalah yang di hadapi.

Dengan diketahui bahwa masih di temukan responden yang belum mendapatkan konseling oleh tenaga kesehatan, di antaranya adalah waktu yang khusus di sediakan untuk responden dalam menerima konseling di anggap kurang, selain itu waktu dalam menerima konseling juga di anggap penyebab lainnya.

Penyebab lainnya juga cukup mempengaruhi kurangnya konseling oleh tenaga kesehatan adalah tenaga kesehatan yang di anggap sulit di hubungi bila sewaktu-waktu responden mempunyai keluhan. Hal tersebut di karenakan jumlah bidan yang ada masih terbatas yaitu 20 orang dan harus menangani 62 posyandu dari 15 desa. Hasil tersebut juga di dukung dari pertanyaan yang di ajukan oleh peneliti terhadap responden, dimana hampir semua responden mengatakan bahwa ketiga hal tersebut merupakan beberapa hal yang mempengaruhi kurang maksimalnya pelaksanaan konseling di puskesmas Sidomulyo. Namun hal ini bertolak belakang dengan temuan peneliti di lapangan di temukan bahwa masih banyak responden yang sudah mendapat konseling $\mathrm{KB}$ khususnya IUD tetapi memilih Alkon lain, karena mereka belum benar-benar mengerti 
tentang keunggulan dan kerugian masingmasing alkon yang cocok dengan kondisi responden saat ini, begitu juga sebaliknya yang tidak mendapat konseling tapi memilih IUD di karenakan responden mendapat informasi berdasarkan pengalaman di lingkungan terdekat atau kerabat responden itu sendiri, begitu pula pekerjaan dan paritas ternyata cukup besar mempengaruhi keberhasilan konseling tersebut. Dimana dari hasil yang di temukan di dapatkan bahwa sebagian responden bekerja sebagai ibu rumah tangga ,yang berarti waktu yang di miliki responden untuk mendapatkan konseling dari tenaga kesehatan sebenarnya cukup banyak. Meskipun disayangkan bahwa keberhasilan konseling di puskesmas Sidomulyo masih kurang ,namun di harapkan upaya dapat di lakukan adalah dengan terus meningkatkan penyuluhan kesehatan masyarakat khusus nya tentang pentingnya konseling dalam menentukan penggunaan alat kontrasepsi.

Peneliti menilai bahwa selain dukungan tenaga kesehatan ,dukungan masyarakat khususnya calon akseptor KB IUD sangat di harapkan demi keberhasilan penggunaan alat kontrasepsi khususnya IUD. Untuk itu peneliti menyimpulkan bahwa untuk meningkatkan keberhasilan pelaksanan konseling dan pemilihan alat kontrasepsi IUD di Puskesmas Sidomulyo perlu terus di upayakan pelaksanaan kegiatan berupa pemberian informasi baik secara langsung oleh tenaga kesehatan maupun tidak .Secara langsung dapat di lakukan dengan mengadakan penyuluhan seperti Puskesmas, Posyandu, dan tempat lainnya sedangkan secara tidak langsung dapat di lakukan dengan memasang poster-poster di tempattempat umum yang mudah di lihat dan di baca serta dengan membagikan leaflet tentang penting nya melakukan konseling dalam pemilihan alat kontrasepsi.

\section{KESIMPULAN}

Berdasarkan hasil penelitian dan pembahasan yang telah diuraikan ,maka peneliti menyimpulkan ada hubungan yang bermakna dan berarti antara konseling dengan pemilihan Alkon IUD pada akseptor KB di Puskesmas Sidomulyo Kecamatan Sidomulyo kabupaten Lampung Selatan ( $p$ Value=0,031).dan di dapat OR sebesar 1,9 yang artinya ada kemungkinan responden yang di beri konseling berpeluang 1,9 kali lebih besar untuk memilih IUD di banding dengan responden yang tidak mendapat konseling $\mathrm{KB}$ untuk memilih IUD

Oleh karena konseling cenderung memiliki hubungan dengan pemilihan Alkon IUD, maka perlu di lakukan upaya -upaya untuk penanggulangannya, berkaitan dengan hal tersebut peneliti menyarankan bidan dan tenaga kesehatan yang terkait agar terus mengupayakan peningkatan pelayanan kesehatan kepada masyarakat, berupa 
penyuluhan tentang pentingnya melakukan konseling dalam menentukan penggunaan alat kontrasepsi. Memberikan informasi kepada masyarakat tentang manfaat dan keuntungan baik secara lisan (penyuluhan di puskesmas, Posyandu dan tempat pelayanan kesehatan lainnya) ataupun tulisan (memasang poster dan membagikan leaflet).

\section{KEPUSTAKAAN}

Badan Pusat Statistik. (2003). Statistik Kesejahteraan Rakyat 'Welfare Statitistics', Jakarta : BPS.

Bessinger, R. E., Betrrand, J. T., (2001). Monitoring Quality Of Care In Family Planning Programs. Tulane University

BKKBN. (2008). Panduan Penggarapan Kelompok KB Pria. Jakarta : Direktorat Peningkatan Partisipasi Pria-Badan Koordinasi Keluarga Berencana. . (2008). Panduan Peningkatan

Partisipasi Pria dalam KB dan Kesehatan Reproduksi. Jakarta : Direktorat Peningkatan Partisipasi PriaBadan Koordinasi Keluarga Berencana (BKKBN). (2009). Rencana Operasional Program KB Nasional Provinsi Lampung. Lampung : Badan Koordinasi Keluarga Berencana (BKKBN) Provinsi Lampung.
Departemen Kesehatan RI. (2005). Profil Kesehatan Indonesia. 2004, Depkes RI, Jakarta: Departemen Kesehatan RI .(2006). Profil Kesehatan Indonesia 2005, Jakarta : Depkes RI, Dinas Kesehatan Provinsi Lampung. (2006).

Profil Kesehatan Lampung Tahun 2006, Lampung : Dinkes Provinsi Lampung

Dinas Kesehatan Kabupaten Lampung Selatan. (2008). Profil Kesehatan Kabupaten Lampung Selatan Tahun 2007. Kalianda : Dinkes Lamsel

Effendi, Onong, Uchjaya. (1999). Ilmu Komunikasi Teori dan Praktek. Bandung. PT. Remaja Rosdakarya. 